\title{
Assessing the Potential Impact of the BioSense 24-hour Rule Using NC DETECT ED Data
}

\author{
Amy Ising ${ }^{\star 1}$, Clifton Barnett ${ }^{1}$, Dennis Falls ${ }^{1}$, Anna E. Waller ${ }^{1}$, John Wallace ${ }^{2}$ and Lana \\ Deyneka $^{2}$
}

${ }^{1}$ Emergency Medicine, UNC Chapel Hill, Chapel Hill, NC, USA; ${ }^{2}$ North Carolina Division of Public Health, NC DHHS, Raleigh, NC, USA

\section{Objective}

NC DETECT emergency department (ED) data were analyzed to assess the impact of applying the BioSense "24-hour rule" that combines ED visits into a single visit if the patient ID and facility ID are the same and the earliest recorded dates occur within the same 24-hour time frame. [1]

\section{Introduction}

Per a frequently asked questions document on the ISDS website [1], approximately two thirds of HL7 records received in BioSense do not provide a Visit ID. As a result, BioSense data processing rules use the patient ID, facility ID and earliest date in the record to identify a unique visit. If the earliest dates in records with the same patient ID and facility ID occur within the same 24-hour time frame, those two visits are combined into one visit and the earliest date will be stored. The ED data sent by hospitals to NC DETECT include unique visit IDs and these are used to identify unique visits in NC DETECT. These data are also sent twice daily to BioSense. In order to assess the potential differences between the NC DETECT ED data in NC DETECT and the NC DETECT ED data in BioSense, an initial analysis of the 24-hour rule was performed.

\section{Methods}

4,822,347 unique ED visits from 2013 NC DETECT data were included in this analysis. The 24-hour rule was applied to these visits; if $\mathrm{ED}$ visit records met the 24-hour rule inclusion criteria, the data from only the first ED visit was kept. Counts were compared to the data based on unique Visit ID to the data based on the 24-hour rule by ED disposition, age group, syndrome, payor source, transport mode, county of residence and patient sex. The percentage of ED visits "lost" to the 24-hour rule was calculated.

\section{Results}

After applying the 24-hour rule, the 4,822,437 ED visits in 2013 were reduced to $4,740,250$, a $1.7 \%$ reduction in ED visits. Table 1 shows the lowest and highest \% loss of ED visits by data element.

\section{Conclusions}

Combining ED visits by the same patient that occur at the same facility within 24 hours reduces the overall ED visit count in NC by approximately $1.7 \%$. The percentage of ED visits lost is higher for certain types of visits, e.g. behavioral health, healthcare utilization, GI illness and varies significantly across counties in NC. Additional research and documentation are needed to determine if this initial analysis is an accurate understanding of the BioSense 24-hour rule, and the potential impact this has on timely surveillance for select indicators.
Table 1: Percentage of ED Visits Lost After Applying the 24-hour rule, by Select Data Elements

\begin{tabular}{|c|c|c|}
\hline \begin{tabular}{|l|} 
Data Element \\
\end{tabular} & Lowest \% Loss (\%) & Highest \% Loss (\%) \\
\hline Age Group & $10-14$ year-olds $(1.1 \%)$ & $25-44$ year-olds $(1.9 \%)$ \\
\hline Patient County & $\begin{array}{r}\text { Montgomery }(0.97 \%) ; \\
\text { Currituck }\end{array}$ & $\begin{array}{r}\text { Forsyth }(3.77 \%) \text {; Sto } \\
\text { Alleghany }(2 .\end{array}$ \\
\hline $\begin{array}{c}\text { ED } \\
\text { Disposition }\end{array}$ & $\begin{array}{c}\begin{array}{c}\text { Transferred/discharged to home under care of a } \\
\text { home IV drug therapy provider }(0.02 \%) \text {; admitted } \\
(0.18 \%)\end{array}\end{array}$ & $\begin{array}{c}\text { Left without being seen }(9.59 \%) ; \\
\text { Left Against Medical Advice } \\
(7.62 \%)\end{array}$ \\
\hline & Worker's compensation (1.10\%) & Missing $(4.10 \%)$; Self-pay $(1.82 \%)$ \\
\hline Syndromes & $\begin{array}{l}\text { Water Safety Threats ( } 0 \% \\
\text { Carbon Monoxide Po }\end{array}$ & $\begin{array}{r}\text { Affective Symptor } \\
\text { Refill }(2.18 \%) ; \text { Vol } \\
\text { (2.16 }\end{array}$ \\
\hline $\begin{array}{c}\text { Transport } \\
\text { Mode to ED }\end{array}$ & $\begin{array}{r}\text { Fixed wing air ambulanc } \\
\text { ambulance }(0\end{array}$ & $\begin{array}{l}\text { Missing }(2.49 \%) \text {; Unknown }(2.22 \%) ; \\
\text { Walk-in following public } \\
\text { transportation }(2.06 \%)\end{array}$ \\
\hline Patient Sex & Female (1.6\%) & $\begin{array}{c}\text { Missing (3.95\%); Unknown (2.01\%); } \\
\text { Male }(1.84 \%)\end{array}$ \\
\hline
\end{tabular}

\section{Keywords}

data quality; BioSense; data processing; emergency department data

\section{Acknowledgments}

NC DETECT is funded with federal funds by the North Carolina Division of Public Health, Public Health Emergency Preparedness Grant (PHEP), and managed through a collaboration between NC DPH and the UNC Department of Emergency Medicine Carolina Center for Health Informatics.

\section{References}

1. BioSense v2.0 Webinar: Data Processing [Internet]. Boston: ISDS [cited 2014 Sept 9]. Available from http://www.syndromic.org/ resources/isds-webinars/upcoming-recent/742-biosense2-webinardata-processing.

\section{*Amy Ising}

E-mail: ising@ad.unc.edu 